\title{
Determinants of spatial pattern at different scales in two populations of the marine alga Rissoella verruculosa
}

\author{
Lisandro Benedetti-Cecchi*, Iacopo Bertocci, Stefano Vaselli, Elena Maggi \\ Dipartimento di Scienze dell'Uomo e dell'Ambiente, Via A. Volta 6, 56126 Pisa, Italy
}

\begin{abstract}
Understanding linkages between patterns and processes across scales is an important issue in ecology. We investigated the causes of spatial variation at different scales in 2 populations of the red alga Rissoella verruculosa (Bertoloni) J. Agardh, located on shores about $70 \mathrm{~km}$ apart in the northwest Mediterranean. We used transplantation and removal experiments in combination with measures of recruitment to test whether the similarities of patterns between populations, as documented in previous studies, were produced by the same processes. Results pointed to the importance of pre-emption of the substratum in setting both upper and lower margins of distribution of $R$. verruculosa. Low recruitment contributed to setting lower margins, but did not explain along-shore variation in cover. Intensity of recruitment and post-recruitment mortality were much greater at the northern location in high-shore habitats, whilst fronds attained a larger size at the southern location in low-shore habitats. These data suggested that the processes maintaining the upper and lower margins of distribution of $R$. verruculosa differed between populations, but produced similar patterns at the 2 locations. Thus, similarity of pattern did not imply that the same underlying processes were operating in different places. Identifying the processes that do not leave signatures in existing conditions, but that may do so if conditions change, can increase our ability to understand and predict spatially and temporally variable patterns in assemblages.
\end{abstract}

KEY WORDS: Algae $\cdot$ Biological interactions $\cdot$ Recruitment $\cdot$ Spatial scaling $\cdot$ Rissoella verruculosa $\cdot$ Rocky shores · Transplant experiment

Resale or republication not permitted without written consent of the publisher

\section{INTRODUCTION}

How to relate patterns and processes across scales is a debated issue in ecology. Central to the understanding of this relationship is the extent to which local processes contribute to the generation of large-scale patterns. In other words, do local processes propagate their effects over large spatial scales? If yes, by which mechanisms? Ecologists are just starting to uncover linkages between small-scale processes and largescale patterns (Huston 1999, Wootton 2001), but it remains unclear how common these relationships are in natural systems.

Replicating experiments over a hierarchy of spatial or temporal scales is necessary to compare local pro- cesses and to determine the extent to which they can be generalised (Underwood \& Petraitis 1993, Beck 1997). Technically, this approach requires selecting levels of spatial or temporal replication randomly from populations of possible levels. This procedure is useful to quantify spatial and temporal variance in ecological processes, but does not reveal the causes responsible for the observed variability (Benedetti-Cecchi 2003). Another approach is that of replicating experiments in habitats with contrasting physical/biological settings or along environmental gradients (Borcard et al. 1992, Bell et al. 1993, Horne \& Schneider 1995, Hoagland \& Collins 1997). Examples include studies focusing both on small-scale (e.g. Harley 2003) and large-scale (e.g. Menge et al. 2002) processes. 
Key to the success of any approach is the linkage between the scales of observations and those of experimentation. The spatial and temporal hierarchies over which experiments are conducted must match the scales over which measurements have been taken. Mismatch between these scales would impair the ability of any experiment to explain the original observations (Huston 1999). In contrast, alternating between hierarchical analyses of spatial and temporal patterns and experimental tests of causal effects at the relevant scales can significantly advance our ability to assess the relative importance of different processes across scales (Underwood 1990, Eberhardt \& Thomas 1991, Rastetter et al. 1992, Schneider 1994, Underwood et al. 2000, Fraschetti et al. 2005). Similar approaches have proven successful in explaining spatial or temporal heterogeneity in a number of systems, including kelp forests (Dayton et al. 1984, 1992) sandflat habitats (Thrush et al. 1997, 2000) and rocky intertidal habitats (Underwood et al. 1983, Menge et al. 1999, 2003).

Rissoella verruculosa (Bertoloni) J. Agardh is a red alga endemic to the Mediterranean that plays an important role in structuring mid-shore assemblages (Benedetti-Cecchi 2000). Previous work on this species indicated that most of the variability in percentage cover was at the local scale, among quadrats 10 s to 100s of centimetres apart, both along-shore and across the vertical gradient and among sites 10 s to 100 s of metres apart, whilst variability at the regional scale (among shores 10s to 100s of kilometres apart) was irrelevant (Menconi et al. 1999, Benedetti-Cecchi 2001, Benedetti-Cecchi et al. 2003). Additional data also indicated that patterns in size and biomass of the alga were variable at scales ranging from 10 s of centimetres to 10 s of metres; however, in contrast to percentage cover these variables also differed at the spatial scale of 10s of kilometres (Benedetti-Cecchi et al. unpubl. data).

Results from experiments indicated that Rissoella verruculosa required patches of substratum lacking in erect organisms to become established (BenedettiCecchi 2000). As a consequence, pre-emption of the substratum was important in setting the upper and lower limits of distribution of $R$. verruculosa at 1 location, though these effects were temporally variable (Benedetti-Cecchi et al. 1999). Small-scale variability along the horizontal axis of the shore was determined to a large extent by a combination of spatially (and temporally) variable events of disturbance that provided $R$. verruculosa with suitable patches for colonisation and caused variable interactions with other colonists and grazers (Benedetti-Cecchi 2000).

In the present paper, we further investigate possible causes of variability in cover, size and biomass of 2 populations of Rissoella verruculosa about $70 \mathrm{~km}$ apart in the northwest Mediterranean. These populations could be distinguished on the basis of their size and morphology, with the northern population (located in Punta Bianca) being up to 3 times larger than the southern one (located in Calafuria) (Benedetti-Cecchi et al. unpubl. data). Given these differences in size and morphology and because the 2 locations were physically and biologically distinct (Menconi et al. 1999, Benedetti-Cecchi et al. 2003), one may expect that the processes responsible for spatial pattern in these populations also differ, despite similarities in the resulting patterns of distribution. The main objective of this paper was to distinguish between these alternatives by conducting parallel experiments at Calafuria and Punta Bianca, to examine the role of physical and biological processes in setting the vertical margins of the distribution of $R$. verruculosa and the influence of recruitment in dictating both vertical and horizontal margins. If the processes responsible for spatial variability were the same at the 2 localities, then we would expect similar responses of the 2 populations maintained under the same experimental conditions. Distinct responses would, in contrast, be indicative of quantitative and/or qualitative differences between locations in the processes influencing the spatial pattern of $R$. verruculosa. Thus, this study addresses whether understanding consistency and variation in small-scale processes examined over broad spatial scales can help in understanding large-scale patterns.

\section{MATERIALS AND METHODS}

The study system. The study was conducted at 2 locations in the Ligurian Sea: Calafuria (CF), a few kilometres south of Livorno $\left(43^{\circ} 30^{\prime} \mathrm{N}, 10^{\circ} 20^{\prime} \mathrm{E}\right)$ and Punta Bianca (PB), about $70 \mathrm{~km}$ north of Livorno $\left(44^{\circ} 05^{\prime} \mathrm{N}, 9^{\circ} 59^{\prime} \mathrm{E}\right)$. The substratum was sandstone at $\mathrm{CF}$, while schists and calcareous rocks characterised $\mathrm{PB}$. Tidal ranges were narrow in the study region, with an average amplitude of $25 \mathrm{~cm}$. All the experiments described in this study were done on wave-exposed rocky shores.

The 2 locations supported qualitatively similar assemblages of algae and invertebrates, although relative abundances and vertical patterns of distribution might have differed (Benedetti-Cecchi 2001). The top of the shore was usually dominated by the barnacle Chthamalus stellatus (Poli) (median cover $=67.5 \%$ ) and cyanobacteria (mostly Rivularia spp., median

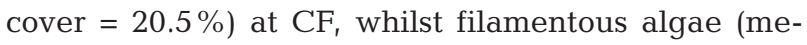
dian cover $=28 \%$ ) and encrusting coralline algae (median cover $=12 \%$ ) dominated at PB. Rissoella verruculosa was common at mid-levels of the shore along with filamentous algae such as Chaetomorpha aerea 
(Dillwyn) Kützing and Polysiphonia spp. and the brown crust Ralfsia verrucosa (Areschoug) J. Agardh. Low levels on the shore were occupied by turf-forming algae (including several species of articulated corallines and filamentous and coarsely branched algae), the canopy-forming alga Cystoseira compressa (Esper) Gerloff et Nizamuddin and the mussel Mytilus galloprovincialis Lamarck. The dominance of turf-forming algae at CF contrasted with the dominance of mussels at PB (Benedetti-Cecchi 2001). The most common grazers were the limpets Patella aspera Roding, $P$. coerulea Linnè and $P$. rustica Linnè. In addition to these general patterns of distribution, there was also considerable variability in the structure of assemblages among patches within heights of the shore (Menconi et al. 1999, Benedetti-Cecchi 2000, 2001).

Rissoella verruculosa (Rhodophyta: Gigartinales) is a perennial alga endemic to the Mediterranean. Its life cycle is characterised by the alternation of 3 generations: the isomorphic gametophytic and sporophytic generations and the distinct carposporophytic generation. The morphology of gametophytes and sporophytes is a coriaceous and elastic thallus, formed by red-brown to green-yellow upright fronds with indented edges, supported by a narrow stipe that arises from a perennial encrusting base. Upright fronds regenerate from the perennial basis in early winter and persist until the beginning of the warm season (June/July). The alga persists as an encrusting base during the summer (these crusts are almost invisible to the unaided eye in the warm season). Sexual reproduction occurs in spring: male gametes (spermatia) fertilise female gametes (carpogonia) on the female gametophyte, giving rise to the carposporophytic generation. Carposporophytes reside in the conceptacles of the female gametophytes and release diploid carpospores, which develop into tetrasporophytes. Tetrasporophytes produce haploid tetraspores that develop into gametophytes. These appear as new crusts on the shore at the beginning of the warm season (Benedetti-Cecchi pers. obs.).

Low-shore transplant experiment. We examined whether interactions with neighbours, as opposed to other biological or physical processes, prevented Rissoella verruculosa from producing persistent patches in the low-shore habitat. We focused on this habitat because the observational evidence available, suggested that $R$. verruculosa could not develop persistent patches low on the shore as a consequence of swamping effects by mussels and turf-forming algae (Benedetti-Cecchi et al. 1999, unpubl. data). Similar effects, in contrast, were less likely to occur in the high-shore habitat that was dominated by barnacles. Although potentially important in preventing the recruitment of $R$. verruculosa (Benedetti-Cecchi et al. 1999; see also the next experiment), barnacles do not interact with the post-recruitment stages of the alga (BenedettiCecchi 2000).

Processes affecting the persistence of Rissoella verruculosa low on the shore were examined with a transplant experiment initiated in December 1997 and conducted in parallel at CF and PB. At each locality chips of rock 5 to $10 \mathrm{~cm}^{2}$ in area and covered by the encrusting base of $R$. verruculosa were chiselled from the midshore habitat and randomly assigned to 4 levels of the factor treatment: (1) chips transplanted in a matrix of surrounding organisms, (2) chips transplanted in clearings, (3) translocated chips and (4) unmanipulated controls. The experimental design included the factors location (2 levels, CF and PB) and site (3 replicated sites within each combination of levels of the other factors), with $\mathrm{n}=5$ replicate chips at each site.

Chips were fastened into chiselled depressions of the rock with epoxy putty (Subcoat-S, Veneziani), as described in previous experiments (Benedetti-Cecchi 2000). Transplanted chips were placed about $10 \mathrm{~cm}$ in vertical extent below the lower margin of the distribution of patches of Rissoella verruculosa, in areas densely colonised by turf-forming algae (dominant at CF) or mussels (dominant at PB when this experiment was carried out). Chips were either left in physical contact with these organisms (i.e. chips were transplanted in a matrix of low-shore organisms) or were placed in circular plots of 20 to $30 \mathrm{~cm}$ in diameter, produced by scraping-off resident organisms from the substratum with a paint scraper (i.e. chips transplanted in clearings). Translocated chips were moved horizontally on the shore and controlled for possible artefacts due to chiselling, fixing with epoxy-putty and moving to another place. Unmanipulated controls consisted of chips collected at the end of the study from natural patches of $R$. verruculosa. Clearings were maintained by removing newly colonising organisms every 2 to $4 \mathrm{wk}$.

In May 1999, after 17 mo since the start, all chips were collected and brought to the laboratory for measurements. Three response variables were quantified for each chip: the length of the largest frond, biomass of erect fronds and percentage cover. Length was measured to the nearest millimetre with a plastic calliper [width was not measured because it was strongly correlated with length, as indicated by previous experiments (Benedetti-Cecchi et al. unpubl. data)]. Biomass was measured as wet mass to the nearest $0.001 \mathrm{~g}$. Cover was measured by placing on each chip a $3 \times 3$ $\mathrm{cm}$ frame divided into 36 squares of $0.5 \times 0.5 \mathrm{~cm}$ and counting the number of squares in which the alga was present (final data were expressed as percentages).

Two main predictions were tested with this experiment. If interactions with other organisms were impor- 
tant in preventing Rissoella verruculosa from becoming established in the low-shore habitat and the size of clearings was appropriate to reduce this effect, then one would observe larger fronds and larger values of biomass and percentage cover for chips transplanted into clearings compared to chips transplanted into a matrix of other organisms. In contrast, if biological interactions were not important, there would be no difference between chips surrounded by low-shore organisms and those in clearings, but both would be different from the controls if the lower limit of $R$. verruculosa was set by physical processes. Of course, the comparison between cleared and uncleared plots in the lowshore habitat might also reveal positive effects of lowshore organisms on $R$. verruculosa, although this result would not explain the original observation (i.e. the lack of $R$. verruculosa low on the shore).

Pre-emption of the substratum. This experiment investigated whether pre-emption of the substratum by sessile organisms influenced the vertical patterns of distribution and abundance of Rissoella verruculosa. A previous study conducted at CF (Benedetti-Cecchi et al. 1999) indicated that this alga could extend its vertical range if organisms living beyond the upper and lower boundaries were removed. Here, we examine whether these results are consistent across sites and among repetitions of the experiment, both at $\mathrm{CF}$ and $\mathrm{PB}$.

In November 1997, 8 sites (stretches of coast of 10 to $15 \mathrm{~m}$ ) containing patches of Rissoella verruculosa were selected at CF and assigned randomly to each of 2 starting dates of the experiment, November 1997 and February 1998, with 4 sites per date. Six plots of $8 \times$ $12 \mathrm{~cm}$ (with the longer side placed horizontally on the shore) were located haphazardly at each site and marked permanently at their corners with epoxy putty (Subcoat-S, Veneziani). Plots were placed just above the upper margins of distribution of $R$. verruculosa at 2 of the 4 sites (selected at random) and below the lower margins at the remaining 2 sites. Organisms were removed with hammer and chisel at the start of the experiment in 3 of the 6 quadrats chosen randomly at each site, whereas they were left undisturbed in the remaining 3 quadrats that served as controls. Barnacles were the dominant organisms just above the upper margins of distribution of $R$. verruculosa, whereas encrusting and turf-forming algae dominated below the lower margins. The same design was used at PB, where treatments were initiated in January and in February 1998. Barnacles still dominated high on the shore, whereas mussels occupied most of the substratum in the low-shore habitat.

The design of this experiment included the following factors: (1) location (2 levels, CF and PB), (2) date (2 dates within each location), (3) height (2 levels, upper and lower margins, respectively), (4) site (2 sites within each combination of height, date and location) and (5) treatment (2 levels, removal and control), with $\mathrm{n}=3$ replicate units in each combination of site and treatment.

Plots were sampled approximately 2 yr after initiation. This period encompassed the timing of reproduction of gametophytes (spring), recruitment of tetrasporophytes (late spring, early summer) and growth of upright fronds (early winter). Sampling was undertaken by superimposing onto each plot a plastic frame of $8 \times 12 \mathrm{~cm}$ with 96 holes of $10 \times 10 \mathrm{~mm}$ and counting the number of holes in which Rissoella verruculosa was present. Final abundance was expressed as percentage cover.

Patterns of recruitment at local scales. The main purpose of this experiment was to investigate whether lack of recruitment could explain along-shore discontinuities in the distribution of Rissoella verruculosa at the scale of 10 s of metres. We also examined whether recruitment was implicated in maintaining vertical patterns of distribution and abundance of $R$. verruculosa. If limited recruitment contributed to maintaining local patterns of variability, then one would expect fewer germlings of $R$. verruculosa far from natural patches of the alga compared to numbers observed in close proximity to these patches. Similarly, fewer germlings would be expected beyond the upper and lower margins of distribution of the alga, compared to the mid-shore habitat with $R$. verruculosa.

These hypotheses were tested by examining patterns of recruitment on artificial substrata that were preferred to natural substrata in order to minimise the influence of interactions with other organisms. In June 1999, a total of 120 ceramic tiles of $5 \times 5 \mathrm{~cm}$ were fastened into chiselled depressions of the substratum with epoxy putty (Subcoat-S, Veneziani) at CF and PB. Tiles were allocated to the following levels of experimental factors: (1) habitat (with 4 levels, mid-shore habitat within patches of Rissoella verruculosa, mid-shore habitat without $R$. verruculosa, above patches and below patches), (2) location (CF and $\mathrm{PB}$ ), (3) site (3 replicate sites within each combination of habitat and location), with $\mathrm{n}=5$ replicate tiles at each site. Sites were $10 \mathrm{~s}$ to $100 \mathrm{~s}$ of metres apart, and those without $R$. verruculosa were at least $5 \mathrm{~m}$ apart from mature patches of the alga.

Tiles were sampled photographically in December 1999 using a Nikonos V camera equipped with an electronic flash and an extension tube for macro-photography (1:2 reproduction ratio with a $35 \mathrm{~mm}$ lens). Slides were projected onto a screen, and the germlings were counted. Tiles were inspected again in March 2003, when the percentage cover of Rissoella verruculosa was measured with the aid of a plastic frame of $5 \times 5 \mathrm{~cm}$ divided into 25 quadrats of $10 \times 10 \mathrm{~mm}$, as described in 
the previous experiment (see 'Materials and methods; Pre-emption of the substratum').

Statistical analyses. Data were analysed with mixed models of analysis of variance. Treatment, location and height were treated as fixed effects in analyses, whereas site and date were random sources of variation. Location was considered fixed because hypotheses were specific for the populations of Rissoella verruculosa of CF and PB. Thus, results apply only to these populations and not to others that might have occurred elsewhere in the north-western Mediterranean.

Data on size, biomass and cover of Rissoella verruculosa from the low-shore transplant experiment were analysed with a 3-factor design, with treatment and location as crossed factors and site nested within the location $\times$ treatment interaction.

A 5-factor model of analysis was used to examine the influence of pre-emption of the substratum on variation in cover of Rissoella verruculosa across the vertical gradient of the shore. Location, height and treatment were crossed factors, date was nested within location and crossed with height, whereas site was nested within the height $\times$ date(location) term.

Finally, patterns of recruitment were examined with a 3-factor ANOVA in which location and habitat were crossed factors and site was nested within the location $\times$ habitat interaction.

Denominators for F-ratios were derived from expected mean squares for each model of analysis (Winer et al. 1991, Underwood 1997). Cochran's C-test was used to examine whether variances were homogeneous across levels of experimental factors. When the assumption of homogeneity of variances was violated, data were transformed and the assumption was checked again. Analyses were done on transformed data if the transformation effectively removed heterogeneity, otherwise untransformed data were analysed. When appropriate, SNK tests were performed for a posteriori multiple comparisons of the means. All tests were done at $\alpha=0.05$.

A word of clarification is necessary to justify why data on percentage cover of Rissoella verruculosa at CF and PB were analysed simultaneously, generating tests of the main effect of location and its interaction with other factors on abundance. Because patterns of abundance were similar between locations, there was no observational basis to justify a comparison between CF and PB either in large-scale or small-scale patterns of abundance and distribution. We decided to include data from the 2 locations in the same analytical framework for 2 reasons. First, this was likely to increase the statistical power of several tests. Second, the fact that mature populations of the alga had similar patterns of abundance at CF and PB did not exclude the possibility that the processes contributing to these patterns differed between locations.

\section{RESULTS}

\section{Low-shore transplant experiment}

Several chips transplanted in clearings at PB became swamped by mussels and filamentous algae despite our attempts to maintain the surrounding substratum clear of organisms. Hence, potential negative interactions with other organisms might still have affected Rissoella verruculosa in this treatment (see 'Discussion; Local determinants of spatial pattern'). Whilst no fronds survived in uncleared plots at PB, very short fronds developed in cleared plots at this locality (Fig. 1A). Short fronds were also observed in uncleared plots at $\mathrm{CF}$, whereas removal of surrounding organisms increased mean length to values comparable to those of control plots at CF (Fig. 1A). These patterns occurred over a background of large and significant amounts of variation among sites and did not result in a significant treatment $\times$ location interaction (Table 1 ). There was, however, a significant main effect of treatment, with chips transplanted into uncleared patches differing from those of the control and disturbed treatments that were similar to each other (SE for comparison $=0.611$, SNK test). Chips transplanted into cleared patches were not consistently assigned to any of the 2 previous groups of treatments by the multiple comparison test.

Differences in biomass and cover of Rissoella verruculosa closely mimicked those in length, with a significant main effect of treatment in both cases (Fig. 1B,C, Table 1). However, in contrast to the analysis on percentage cover in which the SNK test could not rank treatment means consistently, here multiple comparison tests indicated significantly lower values of biomass for chips transplanted into uncleared patches than they did for chips in the other treatments, which did not differ significantly among each other (SE for comparisons: biomass $=0.120$, cover $=5.867$ ).

\section{Pre-emption of the substratum}

Clearing patches of substratum beyond the upper and lower margins of the distribution of Rissoella verruculosa had temporally and spatially variable effects, as indicated by the significant treatment $\times$ date(location) interaction (Fig. 2, Table 2). Multiple comparison tests detected a significant increase in cover of the alga in clearings produced high on the shore on Date 1 (January 1998) at PB (Fig. 2A) and in clearings produced low on the shore on Date 2 (February 1998) at CF (Fig. 2B) (SE for comparison $=0.187$ ). Treatments had similar effects across sites, as indicated by lack of significance of the treatment $\times$ site interaction (Table 2). Finally, pat- 

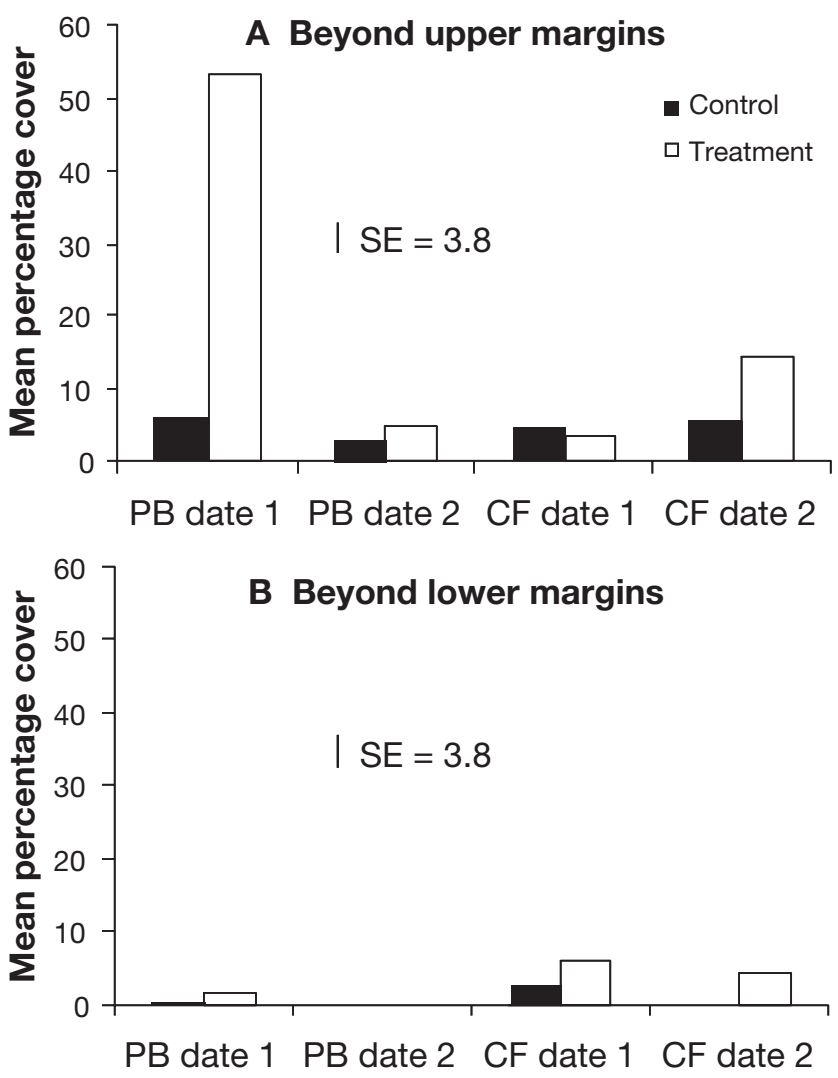

Fig. 2. Rissoella verruculosa. Mean percentage cover in control and removal plots established beyond (A) the upper and (B) lower margins of distribution after 2 yr from each of 2 starting dates at PB and 2 starting dates at CF. Error bars are the squared roots of the ratios between the Treatment $x$ Site(Height $\times$ Date(Location)) terms in Table 2 and the number of observations used to calculate treatment means $(n=6)$. See legend of Fig. 1 for abbreviations

Table 2. Rissoella verruculosa. ANOVA on the effects of clearing patches of substratum on the vertical range of distribution

\begin{tabular}{|c|c|c|c|c|}
\hline Source of variation & df & MS & $F$ & $\mathrm{p}$ \\
\hline Location & 1 & 2.5 & 0.9 & $>0.4$ \\
\hline Date(Location) & 2 & 2.9 & 3.3 & $>0.05$ \\
\hline Height & 1 & 20.1 & 16.9 & $>0.1$ \\
\hline Height $\times$ Location & 1 & 1.2 & 0.5 & $>0.3$ \\
\hline Height $\times$ Date(Location) & 2 & 2.2 & 2.5 & $>0.1$ \\
\hline Site $($ Height $\times$ Date $($ Location $))$ & 8 & 0.9 & 1.2 & $>0.3$ \\
\hline Treatment & 1 & 4.7 & 7.6 & $>0.2$ \\
\hline Treatment $\times$ Location & 1 & 0.6 & 0.2 & $>0.6$ \\
\hline Treatment $\times$ Date(Location) & 2 & 2.6 & 6.2 & $<0.05$ \\
\hline Treatment $\times$ Height & 1 & 0.6 & 0.3 & $>0.6$ \\
\hline Treatment $\times$ Height $\times$ Location & 1 & 1.7 & 1.6 & $>0.3$ \\
\hline Treatment $\times$ Height $\times$ Date(Location) & 2 & 1.1 & 2.6 & $>0.1$ \\
\hline Treatment $\times$ Site $($ Height $\times$ Date $($ Location $))$ & 8 & 0.4 & 0.6 & $>0.7$ \\
\hline Residual & 64 & 0.7 & & \\
\hline $\begin{array}{l}\text { Cochran's } C \text {-test } \\
\text { Transformation }\end{array}$ & & \multicolumn{3}{|c|}{$\begin{aligned} C= & 0.1421, \mathrm{p}>0.05 \\
& \ln (x+1)\end{aligned}$} \\
\hline
\end{tabular}

mostly in the high-shore habitat, whereas all recruits had disappeared from tiles placed in the mid-shore habitat outside natural patches of $R$. verruculosa and in the low-shore habitat.

\section{DISCUSSION}

The results of this study indicated that interactions with sessile species were implicated in maintaining both upper and lower margins of distribution of Rissoella verruculosa and that limited recruitment contributed to setting lower margins, but did not explain horizontal variation in distribution. The results also suggested that different processes might have affected the distribution, abundance and size of $R$. verruculosa across the vertical gradient of the shore at $\mathrm{PB}$ and $\mathrm{CF}$, although the resulting patterns were similar at the 2 locations. These findings have important implications for understanding local determinants of spatial pattern and the linkages between pattern and process across scales.

\section{Local determinants of spatial pattern}

Investigations in rocky intertidal habitats have generated 2 main paradigms to explain variation across the vertical gradient of the shore and horizontal patchiness within vertical margins. The first paradigm established that biological interactions such as predation and competition were the main processes determining the lower margins of distribution of species, whereas physical factors such as aerial exposure and desiccation were implicated in setting the upper margins (Connell 1972, Paine 1974, Schonbeck \& Norton 1978, Lubchenco 1980). The second paradigm emphasised the importance of physical and biological disturbance in preventing competitive exclusion (Dayton 1971, Connell 1978, Lubchenco 1978), in creating opportunities for distinct patterns of recovery even in nearby patches of habitats (Sousa 1979a) and, hence, in explaining both patchiness and coexistence of species over relatively small spatial scales (Sousa 1979b). Variability in dispersal and recruitment was then integrated into existing conceptual models as an overarching process capable of explaining both vertical and horizontal patterns of variation (Grosberg 1982, Underwood \& Denley 1984, Gaines et al. 1985, Menge \& Sutherland 1987). 

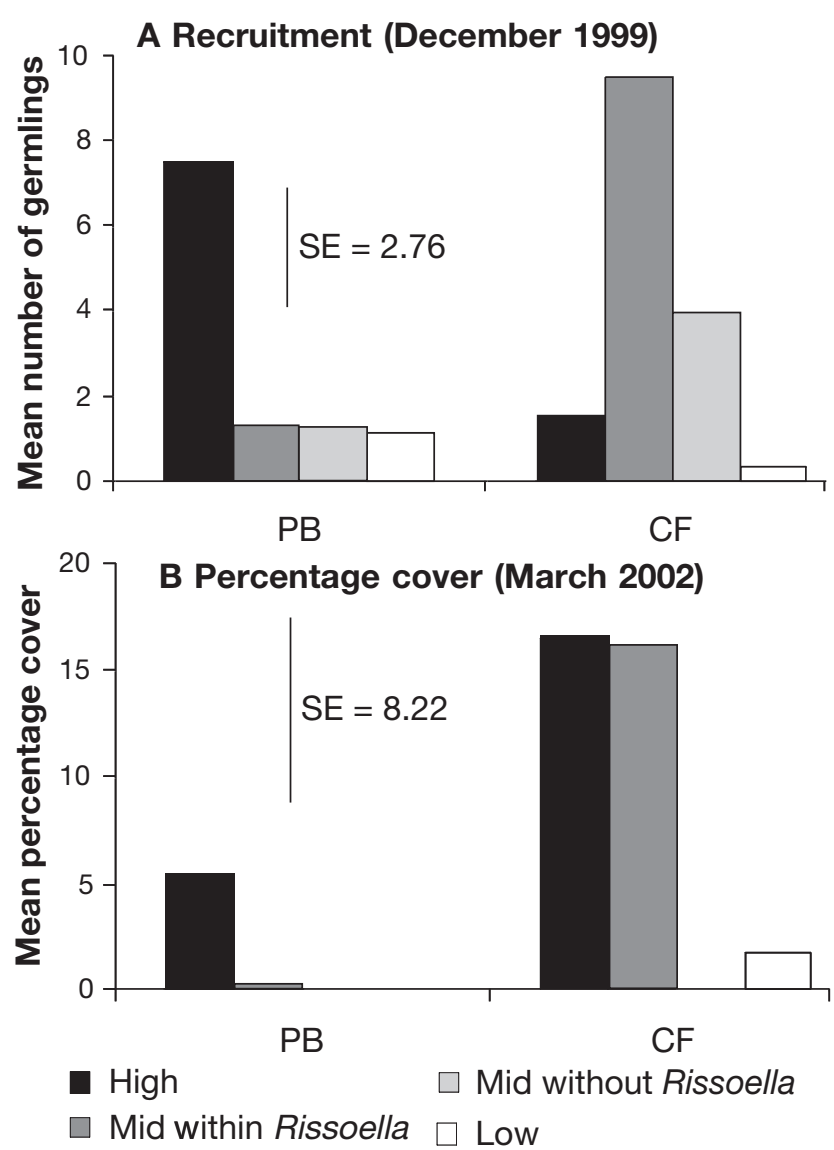

Fig. 3. Rissoella verruculosa. (A) Mean number of recruits and (B) mean percentage cover of the alga on tiles placed in different positions of the shore at PB and CF. Error bars are the squared roots of the ratios between the mean squares of the Site(Habitat $\times$ Location) terms (as indicated for recruitment in Table 3 ) and the number of observations used to calculate treatment means $(n=15)$. See legend of Fig. 1 for abbreviations

Though both paradigms have received support from many studies, some investigations have provided evidence for alternative explanations of patterns of variability and coexistence of species in rocky intertidal habitats. For example, grazing rather than physical factors maintained the upper limit of distribution of some species of algae on rocky shores in Australia (Underwood \& Jernakoff 1981). Though this interaction focused on low-shore organisms, it was a biological process that prevented algae from extending upwards on the shore. Similarly, physiological stress and low productivity, rather than disturbance, can prevent competitive exclusion, promoting coexistence of species in systems where space is limited. Dudgeon et al. (1999), for example, found that coexistence of 2 intertidal algae at mid-shore levels on rocky coasts in the Gulf of Maine, Chondrus crispus and Mastocarpus stellatus, was best explained in terms of limited production rather than mortality from disturbance. C. crispus, however, prevented the establishment of $M$. stellatus lower on the shore and disturbance would have been necessary for $M$. stellatus to colonise this habitat.

Interactions with resident organisms were important in setting both the upper and lower margins of distribution of Rissoella verruculosa. When this alga was transplanted outside its lower margin of distribution, fronds could develop and persist only if mussels and turf-forming algae were removed from the substratum. At PB, mussels eventually closed over those clumps that developed in uncleared plots, and we found difficulties in preventing overgrowth also in plots allocated to the cleared treatment. Many transplanted chips were swamped by mussels and filamentous algae at PB (Benedetti-Cecchi \& Bertocci pers. obs.), and this could explain why cleared plots at this locality had less $R$. verruculosa than those at $C F$, where treatments were maintained more efficiently. Despite these differences, analyses indicated a significant main effect of treatment, but no treatment $\times$ location interactions. The analysis of biomass, in particular, indicated significantly lower values in uncleared than in cleared plots that were not distinguishable from control and disturbed treatments. Similar interactions were described by Harley (2003) in a study on spatial distribution of Mazzaella parskii on Tatoosh Island (USA), where mussels overgrew low-shore transplants of this alga. These effects were amplified by damage from herbivores, a pattern that was not observed for $R$. verruculosa. This species was, in fact, positively affected by grazers that enhanced colonisation by preventing dominance of filamentous algae (Benedetti-Cecchi 2000).

In contrast to herbivory, limited recruitment contributed to maintain the lower limit of distribution of Rissoella verruculosa. Two lines of evidence supported this view. First, pre-emption of the substratum appeared unimportant low on the shore, as the effect of removing resident organisms was generally minimal (though occasionally significant), outside the lower

Table 3. Rissoella verruculosa. ANOVA on mean number of germlings recruiting in different habitats

\begin{tabular}{|lrrrr|}
\hline Source of variation & df & MS & $F$ & $\mathrm{p}$ \\
\hline Habitat & 3 & 3.689 & 2.3 & $>0.1$ \\
Location & 1 & 0.885 & 0.6 & $>0.4$ \\
Habitat $\times$ Location & 3 & 5.340 & 3.3 & $<0.05$ \\
Site $($ Habitat $\times$ Location) & 16 & 1.598 & 2.2 & $<0.05$ \\
Residual & 96 & 0.734 & \\
Cochran's $C$-test & \multicolumn{5}{c}{$\begin{array}{l}\text { ln }(x+1) \\
\text { Transformation }\end{array}$} \\
\hline
\end{tabular}


limit of distribution of the alga. Second, only few germlings recruited on experimental tiles that were placed low on the shore.

Pre-emption of the substratum was clearly implicated in setting the upper margin of distribution of Rissoella verruculosa. Removal of barnacles high on the shore resulted in colonisation of $R$. verruculosa. This effect was variable from date to date, and the analysis also failed to detect differences between heights on the shore. However, when coupled with data from the ceramic tiles, these patterns clearly indicated that neither recruitment, nor physical factors, prevented $R$. verruculosa from becoming established in the high-shore habitat. The alga did extend its upper margin of distribution if patches of open space were made available for colonisation, either by removing resident organisms or by exposing new substrata (see also Benedetti-Cecchi et al. 1999). When the ceramic tiles were revisited after nearly 4 yr following deployment, $R$. verruculosa had grown to an adult size in the high-shore habitat at both locations, and, at $\mathrm{CF}$, tiles placed within and above natural patches of the alga had comparable values of percentage cover. Our results clearly indicated that biological interactions were the main forces preventing the upward extension of $R$. verruculosa at $\mathrm{PB}$ and CF.

Limitation of recruitment did not explain alongshore variation in cover of Rissoella verruculosa. Tiles placed at mid-shore levels away from natural patches of the alga had nearly the same number of recruits as those placed within patches at PB and larger numbers than those placed high on the shore at CF. Thus, postrecruitment mortality was responsible for horizontal variation in the distribution of adult $R$. verruculosa. The causes underlying these patterns were unclear. Previous studies indicated that small-scale patchiness and along-shore variability in the distribution of $R$. verruculosa could originate from variable patterns of colonisation after disturbance and from biological and physical differences in microhabitat (Benedetti-Cecchi 2000). R. verruculosa did not become established in patches heavily colonised by filamentous algae and attained low cover on horizontal substrata, where drainage of seawater was slow. In contrast, the alga was abundant on outcrops of rock and on sub-horizontal substrata. The tiles used in the present study were stratified in experimental areas that shared similar macroscopic features, apart from the presence or absence of $R$. verruculosa.

Harley (2003) discussed a conceptual model to explain directional changes in distribution of populations that are exposed to strong gradients in a direction perpendicular to that of the change. According to this model, horizontal variation in intertidal organisms would reflect the effects of physical and biological pro- cesses that operate independently to set upper and lower boundaries. Horizontal margins of distribution occur when boundaries converge. If Harley's model is correct, then horizontal discontinuities in the distribution of Rissoella verruculosa should be the result of the same processes implicated in maintenance of the upper and lower boundaries of the alga. This provides clues for future experimental tests on the causes of along-shore variability in the distribution of $R$. verruculosa at $\mathrm{PB}$ and $\mathrm{CF}$.

\section{Understanding processes in the absence of patterns}

Differences in patterns of recruitment between $\mathrm{CF}$ and $\mathrm{PB}$ reinforced the results of the transplant experiment, suggesting that the processes responsible for vertical spatial patterns differed qualitatively and/or quantitatively between locations. Intensity of recruitment and post-recruitment mortality in the high-shore habitat were much larger at PB than at CF. A companion study (Benedetti-Cecchi et al. unpubl. data) also indicated that fronds transplanted to the high-shore habitat grew to a larger size at PB than at CF, whilst the opposite occurred in the low-shore habitat. These patterns were observed only under experimental conditions, whereas the inability of Rissoella verruculosa to colonise high on the shore under natural settings produced sharp upper boundaries that did not differ between locations. Thus, phenomenology was silent about large-scale differences in local processes that could be revealed only when the environment was modified experimentally.

These outcomes have important implications for the logical connections between observations, theory and hypothesis-testing (Underwood 1990, Peckarsky 1998, Ford 2000). Lack of patterns prevents the formulation of explanatory models and subsequent experimental scrutiny. As a consequence, distinct processes that result in similar patterns may be difficult to reveal if observations are restricted to the most shallow phenomenology of nature. While ecologists must guarantee rigor and logic in hypothesis-testing, they seem to need a broader concept of observation to uncover processes that do not leave signatures in existing conditions, but that may do so if conditions change. To expand current ideas on the nature of ecological observations, we suggest that repetition of experiments in space and time should provide the foundation to detect cryptic processes, even if pure phenomenology would not motivate spatial or temporal comparisons. This is different from what was asserted by Peckarsky (1998), who emphasised phenomenological or mechanisticfree experiments. It was by examining alternative mechanisms that we were able to identify differences 
in the processes that maintained cross-shore patterns in abundance and distribution of Rissoella verruculosa

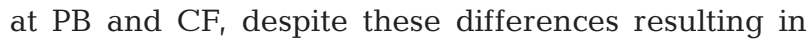
similar large-scale patterns.

Understanding variability in ecological processes is important to increase our ability to make predictions, even when this variability does not produce quantifiable differences in corresponding patterns. For example, increasing the availability of free space in the high-shore habitat should produce a stronger upward shift of Rissoella verruculosa at CF than at PB. This can be predicted on the basis of the different processes that are involved in maintaining similar upper boundaries of distribution of the alga at the 2 locations. Obviously, natural history and knowledge of the system under study should always be coupled with experimentation to identify relevant ecological questions.

\section{Scaling up from local to regional patterns and processes}

The extent to which small-scale processes propagate to generate large-scale patterns is an open question (Huston 1999, Thrush et al. 2000, Wootton 2001). There are 2 major issues related to this. One is that largescale patterns may emerge when small-scale processes operate consistently across locations, so that largescale variation is minimal, as discussed at length by Huston (1999). There is, however, another mechanism that may generate large-scale similarities in spatial pattern that has not received much attention. It is when different processes underlie the same patterns of small-scale variation across locations. This was exemplified by the idiosyncratic nature of the processes that contributed to setting the upper margins of distribution of Rissoella verruculosa at PB and CF and by the relative importance of limited recruitment versus interactions with other sessile species in setting the lower margins, as discussed in the previous sections.

Collectively, our results suggested differences between locations in the intensity and qualitative nature of the processes maintaining the upper and lower margins of distribution of Rissoella verruculosa, despite similarities in the resulting patterns. These outcomes provided the important indication that an analysis of pattern alone may not be sufficient to direct attention to relevant ecological processes. We have advocated a broader definition of the concept of ecological observation, to embrace outcomes of experiments targeting specific ecological processes under different environmental settings. Mechanistic-oriented experiments should be repeated in space and time even if phenomenology is silent about possible small-scale or largescale patterns.
A dual strategy seems therefore necessary to integrate patterns and processes across scales, in which both the causes of variation and those of consistency of local processes at large scales are targeted in experiments. Comparing the sensitivity of a collection of response variables to changes in local processes is a profitable way to make progress in this direction. Natural history will probably be the best guide to anticipating which variables of populations are likely to display reproducible patterns in response to changes of local processes, and which variables will exhibit idiosyncratic responses, at scales relevant to management and conservation of ecological systems.

Acknowledgements. We thank Tasman Crowe, Fiorenza Micheli and the anonymous referees for helpful comments on the manuscript and the numerous people that have assisted with the field work. Special thanks go to Massimo Menconi for his dedication, inspiration and invaluable advise during the early stages of this work. This research was supported by various grants from the University of Pisa.

\section{LITERATURE CITED}

Beck MW (1997) Inference and generality in ecology: current problems and an experimental solution. Oikos 78:265-273

Bell G, Lechowicz MJ, Appenzeller A, Chandler M and 6 others (1993) The spatial structure of the physical environment. Oecologia 96:114-121

Benedetti-Cecchi L (2000) Predicting direct and indirect effects during succession in a midlittoral rocky shore assemblage. Ecol Monogr 70:45-72

Benedetti-Cecchi L (2001) Variability in abundance of algae and invertebrates at different spatial scales on rocky sea shores. Mar Ecol Prog Ser 215:79-92

Benedetti-Cecchi (2003) The importance of variance around the mean effect size of ecological processes. Ecology 84 : 2335-2346

Benedetti-Cecchi L, Menconi M, Cinelli F (1999) Pre-emption of the substratum and the maintenance of spatial pattern on a rocky shore in the northwest Mediterranean. Mar Ecol Prog Ser 181:13-23

Benedetti-Cecchi L, Maggi E, Bertocci I, Vaselli S, Micheli F, Osio GC, Cinelli F (2003) Variation in rocky shore assemblages in the north-western Mediterranean: contrasts between islands and the mainland. J Exp Mar Biol Ecol 293:193-215

Borcard D, Legendre P, Drapeau P (1992) Partialling out the spatial component of ecological variation. Ecology 73: 1045-1055

Connell JH (1972) Community interactions on marine rocky intertidal shores. Annu Rev Ecol Syst 3:169-192

Connell JH (1978) Diversity in tropical rain forests and coral reefs - High diversity of trees and corals is maintained only in a nonequilibrium state. Science 199:1302-1310

Dayton PK (1971) Competition, disturbance, and community organization: the provision and subsequent utilization of space in a rocky intertidal community. Ecol Monogr 41: 351-389

Dayton PK, Currie V, Gerrodette T, Keller BD, Rosenthal R, Ven Tresca D (1984) Patch dynamics and stability of some California kelp communities. Ecol Monogr 54:253-289 
Dayton PK, Tegner MJ, Parnell PE, Edwards PB (1992) Temporal and spatial patterns of disturbance and recovery in a kelp forest community. Ecol Monogr 62:421-445

Dudgeon SR, Steneck RS, Davison IR, Vadas RL (1999) Coexistence of similar species in a space-limited intertidal zone. Ecol Monogr 69:331-352

Eberhardt LL, Thomas JM (1991) Designing environmental field studies. Ecol Monogr 61:53-73

Ford ED (2000) Scientific method for ecological research. Cambridge University Press, Cambridge

Fraschetti S, Terlizzi A, Benedetti-Cecchi L (2005) Patterns of distribution of marine assemblages from rocky shores: evidence of relevant scales of variation. Mar Ecol Prog Ser (in press)

Gaines S, Brown S, Roughgarden J (1985) Spatial variation in larval concentration as a cause of spatial variation in settlement for the barnacle, Balanus glandula. Oecologia 67: $267-272$

Grosberg RK (1982) Intertidal zonation of barnacles: the influence of planktonic zonation of larvae on vertical distribution of adults. Ecology 63:894-899

Harley CDG (2003) Abiotic stress and herbivory interact to set range limits across a two-dimensional stress gradient. Ecology 84:1477-1488

Hoagland BW, Collins SL (1997) Gradient models, gradient analysis, and hierarchical structure in plant communities. Oikos 78:23-30

Horne JK, Schneider DC (1995) Spatial variance in ecology. Oikos 74:18-26

Huston MA (1999) Local processes and regional patterns: appropriate scales for understanding variation in the diversity of plants and animals. Oikos 86:393-401

Lubchenco J (1978) Plant species diversity in a marine intertidal community: importance of herbivore food preference and algal competitive abilities. Am Nat 112:23-39

Lubchenco J (1980) Algal zonation in the New England rocky intertidal community: an experimental analysis. Ecology 61:333-344

Menconi M, Benedetti-Cecchi L, Cinelli F (1999) Spatial and temporal variability in the distribution of algae and invertebrates on rocky shores in the northwest Mediterranean. J Exp Mar Biol Ecol 233:1-23

Menge BA, Sutherland JP (1987) Community regulation: variation in disturbance, competition, and predation in relation to environmental stress and recruitment. Am Nat 130: $730-757$

Menge BA, Daley BA, Lubchenco J, Sanford E, Dahloff E, Halpin PM, Hudson G, Burnaford JL (1999) Top-down and bottom-up regulation of New Zealand rocky intertidal communities. Ecol Monogr 69:297-330

Menge BA, Sanford E, Daley BA, Freidenburg TL, Hudson G, Lubchenco J (2002) Inter-hemispheric comparison of bottom-up effects on community structure: insights revealed using the comparative-experimental approach. Ecol Res $17: 1-16$

Menge BA, Lubchenco J, Bracken MES, Chan F and 9 others (2003) Coastal oceanography sets the pace of rocky intertidal community dynamics. Proc Natl Acad Sci USA 100: 12229-12234

Paine RT (1974) Intertidal community structure: experimental studies on the relationship between a dominant competitor and its principal predator. Oecologia 15:93-120

Editorial responsibility: Roger Hughes (Contributing Editor), Bangor, UK
Peckarsky BL (1998) The dual role of experiments in complex and dynamic natural systems. In: Resetariz WJ Jr, Bernardo J (eds) Experimental ecology. Issues and perspectives. Oxford University Press, Oxford

Rastetter EB, King AW, Cosby BJ, Hornberger GN, O'Neill RV, Hobbie JE (1992) Aggregating fine-scale ecological knowledge to model coarser-scale attributes of ecosystems. Ecol Appl 2:55-70

Schneider DC (1994) Quantitative ecology: spatial and temporal scaling. Academic Press, San Diego

Schonbeck MW, Norton TA (1978) Factors controlling the upper limits of fucoid algae on the shore. J Exp Mar Biol Ecol 31:303-313

Sousa WP (1979a) Disturbance in marine intertidal boulder fields: the nonequilibrium maintenance of species diversity. Ecology 60:1225-1239

Sousa WP (1979b) Experimental investigations of disturbance and ecological succession in a rocky intertidal algal community. Ecol Monogr 49:227-254

Thrush SF, Cummings VJ, Dayton PK, Ford R and 11 others (1997) Matching the outcome of small-scale density manipulation experiments with larger scale patterns an example of bivalve adult/juvenile interactions. J Exp Mar Biol Ecol 216:153-169

Thrush SF, Hewitt JE, Cummings VJ, Green MO, Funnell GA, Wilkinson MR (2000) The generality of field experiments: interactions between local and broad-scale processes. Ecology 81:399-415

Underwood AJ (1990) Experiments in ecology and management: their logics, functions and interpretations. Aust Ecol 15:365-389

Underwood AJ (1997) Experiments in ecology. Their logical design and interpretation using analysis of variance. Cambridge University Press, Cambridge

Underwood AJ, Denley EJ (1984) Paradigms, explanations, and generalizations in models for the structure of intertidal communities on rocky shores. In: Strong DR, Simberloff D, Abele LG, Thistle AB (eds) Ecological communities: conceptual issues and the evidence. Princeton University Press, Princeton

Underwood AJ, Jernakoff P (1981) Effects of interactions between algae and grazing gastropods on the structure of a low-shore intertidal algal community. Oecologia 48: 221-233

Underwood AJ, Petraitis PS (1993) Structure of intertidal assemblages in different locations: How can local processes be compared? In: Ricklefs R, Schutler D (eds) Species diversity in ecological communities. University of Chicago Press, Chicago

Underwood AJ, Denley EJ, Moran MJ (1983) Experimental analyses of the structure and dynamics of mid-shore rocky intertidal communities in New South Wales. Oecologia 56: 202-219

Underwood AJ, Chapman MG, Connell SD (2000) Observations in ecology: you can't make progress on processes without understanding the patterns. J Exp Mar Biol Ecol 250:97-115

Winer BJ, Brown DR, Michelis KM (1991) Statistical principles in experimental design. McGraw-Hill, New York

Wootton JT (2001) Local interactions predict large-scale pattern in empirically derived cellular automata. Nature 413: 841-843

Submitted: November 19, 2004; Accepted: April 7, 2005

Proofs received from author(s): May 6, 2005 